\title{
Comparison and analysis of PMBOK 2013 and ISO 21500
}

\author{
Fereshtheh Tavan $^{\mathrm{a}^{*}}$ and Mokhtar Hosseini ${ }^{\mathrm{b}}$
}

${ }^{a}$ Department of Industrial Engineering, Science and Research Branch, Islamic Azad University, Tehran, Iran ${ }^{b}$ Department of Industrial Engineering, Najaf Abad Branch, Islamic Azad University, Isfahan, Iran

\section{CH R O N I C L E}

Article history:

Received: October 1, 2016

Received in revised format: No-

vember 16, 2016

Accepted: January 7, 2017

Available online:

January 19, 2017

Keywords:

PMBOK

ISO 21500

Project Management Standards

PMI

\section{A B S T R A C T}

\begin{abstract}
Experiences and studies, results and documentations review show that the impress and the strategic level of Project Management (PM) have been increased. Different organizations have introduced various standards for PM. Indeed, the main criterion to select and apply PM standards relies on the standard, depending on the project type and the experiences of PM managers. The primary objective of PM standards is to direct a project into a systematic and regular framework. Application of PM standards makes project easier and gives accurate analysis that provide benefits for executives and gives some managerial approach. The main purpose of this research is to compare and evaluate two most popular and versions of PM standards; namely PMBOK and ISO 21500 .
\end{abstract}

2017 Growing Science Ltd.

\section{Introduction}

Nowadays, importance and necessity of utilization of project management and control is so obvious that they are considered as an essential issue in each organization and requires proper management (Mesquida et al., 2014, 2016). Focusing on specific activities is the main role of project managers, which requires much effort and especial capabilities (Mas et al., 2016). Despite the challenges as entrance to competitive arenas, project managers pay especial attention towards their projects (da Fonseca et al., 2016). The necessity of this article is to give an introduction to standards and their implementation techniques that can help us understand different projects, implementation of project management, creating coordinate and strategic decisions (Chakir et al., 2015). Finally, we can consider the adopted integration of management techniques to prevent the diffusion of personal idea in decisions.

In this paper, we compare PMBOK and ISO 21500 standards, and then similar items and differences between these two are explained. It is tried to show the covered area by each standards that project managers, project team members and anyone who is interested in project management knowledge can utilize these standards. PBOK Gide is the known standard for project management. This standard describes a set of knowledge that is accepted in profession of project management. Project Management

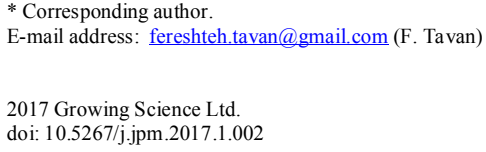


Institute (PMI) considers it as an essential reference of project management for development programs and certificates. ISO 21500 is a project management standard that is published by International Organization for Standards (ISO). In the following, we introduce PMBOK and ISO 21500, and similarities and differences between these two standards are introduced to reveal the strength and the weakness of them and it is utilized for recommending to managers that is mentioned in conclusion section.

Pinto and Dominguez (2012) aimed to contribute to the knowledge on project management practices. The results characterized project management practices in Portuguese metal working companies, by analyzing data of thirty companies from this sector. These results demonstrated that some practices were highly valued especially in the procurement management area.

Sanjuan and Froese (2013) considered the application of project management standards and success factors to the development of a project management assessment tool. The paper describes examples that assess an individual's project management skills and approaches that examine the project management competencies of organizations. Their focus is on assessing the project management practices that have been implemented for specific construction projects. They intend to draw heavily upon established project management standards and project success factors from previous research to provide the specific targets and benchmarks to be assessed. These include the Project Management Body of Knowledge (PMBOK) by the PM Institute, the IPMA Competence Baseline (ICB) by the International PM Association, ISO 9000, and Prince2 by the Office of Government Commerce UK. This paper describes how these standards are integrated into the project management assessment tool. It discusses the theoretical foundations for the project management assessment tool and the methodologies used for developing the tool and for applying the tool to specific project situations (Langston \& Ghanbaripour, 2016).

Grau (2013) presented a paper about standards and excellence in project management. In this paper the new global Standard, the national and international standards and a Project Excellence Modell der IPMA were described. There were also some suggestions on how these standards could be used in a reasonable mix.

Labriet (2012) aimed to highlight the major communalities and differences between the ANSI and the ISO standards, i.e. between the PMBOK® Guide and the ISO/DIS 21500 standard. The important consistency between the ANSI and the ISO standards will definitively help the profession. In the future, if ISO/DIS 21500 becomes the basis of a certification, there will be an advantage for companies to have PMI certified project and program managers onboard. Hammouch et al. (2016) explained how the requirements of ISO 21500 were transformed to develop the PMSPICE Process Reference Model (PRM).

\section{PMBOK and ISO}

\subsection{PMBOK}

The Project Management Body of Knowledge (PMBOK) is the standard for managing most projects most of the time across many types of industries. The standard, describes the project management processes used to manage a project toward a more successful outcome. This standard is unique to the project management field and has correlations with other project management disciplines such as program management and portfolio management. Project management is associated with the implementation of knowledge, skills, tools, and techniques to project activities to reach the project requirements. Project management is accomplished through the appropriate application and integration of the 47 logically grouped project management processes, which are categorized into 5 Process Groups and 10 subject group (Project Management Institute, 2013; Guerra-García et al., 2016; Gonçalves \& Von Wangenheim, 2016a, 2016b). 


\subsection{ISO 21500}

This standard is published by International Organization for Standards at the end of 2012. This standard can be used by deferent organizations that deal with huge projects. This International Standard provides guidance on concepts and processes of project management that are important, and have impact on performance of project and includes 10 subject group and 39 logically group (Hosseini, 2013; OteroMateo et al., 2014)

\section{Methodology}

PMBOK and ISO 21500 are full of contents and concepts. In this article the mentioned standards have divided into 3 sections in order to better and accurate analysis and clearly comparison. Each section involves explanation and tables that shows brief finding. At the end of each section a brief description of the findings is illustrated in table and management recommendations and practical ideas will be offered. The three divided parts are introduced in following:

\section{Part 1: Project Management Concepts and definition}

Project Management Concepts and definition are interpolated in the beginning of both standards. These concepts and definitions provide literature of Project Management science, which give better understand about the knowledge.

\section{Part 2: Project Management Processes}

Both standards express their ideas about project management processes and a resemblance exists on this point. Project management processes are the most important area in Project Management science so, the section 2 is devoted on analyze this part.

\section{Part 3: Project Management knowledge}

Knowledge areas and sub processes are another most important subject in Project Management science. But importance level of part 3 is higher than part 2. So we can say that the Knowledge areas and sub processes are the most importance subject in Project management Science. Fig. 1 illustrates the research systematic approach.

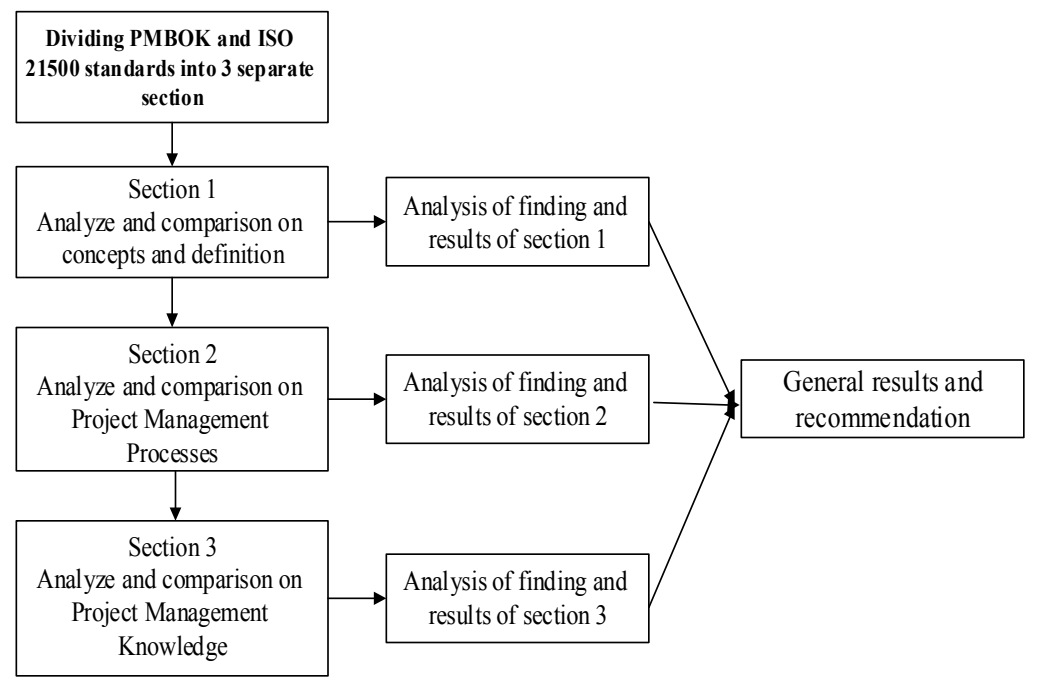

Fig. 1. Research systematic approach 


\section{Research Findings}

\subsection{Findings of section 1: Project Management Concepts and definition}

PMBOK and ISO 21500 explain the basic and the main concepts and the most of the definitions that stand in project management structure clearly such as: Project and Project's characteristic, project management, project management tools, program and portfolio management, strategic and project planning. Both standards transfer these basic concepts to readers and contacts simply and clearly. They draw relationships among projects, programs and portfolios, program management and portfolio management and express difference among them. PMBOK conducts these components to organizational project management (OPM) and this leads to open topic as Project Management Office (PMO) that ISO 21500 pays no attention on it. The difference between project and operation is illustrated and project life cycle is presented with diagram. Supervision of project and stakeholders are discussed. One of the interesting differences between two standards is concerned with project manager issue skills. Competence of project manager is highlighted in PMBOK but ISO 21500 just has a discussion on project personnel. Indeed, PMBOK has a detailed scope rather than ISO 21500. Whenever one organization undertakes a project, it can make impacts on the project's progress called organizational impact. PMBOK introduces organizational impact like: environmental impacts, style, culture and organizational structure. Project information systems application are presented as diagram and noted that have a good communications and widely information flow throughout project can have positive impact on project's progress. Table 1 summarizes the results

\section{Table 1}

Findings of section 1

\begin{tabular}{|c|c|c|}
\hline Concepts and Definition & ISO 21500 & PMBOK \\
\hline Project Definition & $\sqrt{ }$ & $\sqrt{ }$ \\
\hline Project characters & $\sqrt{ }$ & $\sqrt{ }$ \\
\hline Project Management & $\sqrt{ }$ & $\sqrt{ }$ \\
\hline Program Definition & $\sqrt{ }$ & $\sqrt{ }$ \\
\hline Portfolio Definition & $\sqrt{ }$ & $\sqrt{ }$ \\
\hline Program management & $\sqrt{ }$ & $\sqrt{ }$ \\
\hline Portfolio management & $\sqrt{ }$ & $\sqrt{ }$ \\
\hline Organizational project management & - & $\sqrt{ }$ \\
\hline The relations among project, program and portfolio & $\sqrt{ }$ & $\sqrt{ }$ \\
\hline The relations among project management, program management and portfolio management & $\sqrt{ }$ & $\sqrt{ }$ \\
\hline Project management office (PMO) & - & $\sqrt{ }$ \\
\hline Project and operation difference & $\sqrt{ }$ & $\sqrt{ }$ \\
\hline Skills and competence of project manager & - & $\sqrt{ }$ \\
\hline Project team and personnel & $\sqrt{ }$ & $\sqrt{ }$ \\
\hline Project supervision & - & $\sqrt{ }$ \\
\hline Strategic of project & - & $\sqrt{ }$ \\
\hline Opportunity and benefits & $\sqrt{ }$ & - \\
\hline Project information systems & - & $\sqrt{ }$ \\
\hline Organizational impacts & - & $\sqrt{ }$ \\
\hline
\end{tabular}

\subsection{Findings of section 2: Project Management Processes}

Both standards have five project management processes. Each process is explained in details and application of process are also explained. Interactions and relationships of project management process are shown with appropriate diagram and graph. Indeed PMBOK and ISO 21500 have no difference in part 2. If we want to make a difference, we can just say that the titles of tertiary and fourth process are different and the deference is relevant to title and not to concepts. Extracted results of section 2 are illustrated in Table 2.

Table 2

The findings of section 2

\begin{tabular}{ccc}
\hline ISO 21500 & Project management process & PMBOK \\
\hline Initiative & initiative & initiative \\
Planning & Planning & Planning \\
Implementing & Executive & Executive \\
Controlling & Control & Monitoring and control \\
Closing & Closing & Closing \\
\hline
\end{tabular}




\subsection{Findings of section 3: Project Management knowledge}

Part 3 is the most important part because Project Management Knowledge is surveyed in this section. Project managers and project team or members must predominantly pay attention on its concepts to ensure project's progress follow the project plans. Project Management Knowledge in PMBOK is called Knowledge areas and in ISO 21500 is called subject groups. Number of Project Management Knowledge is equal in both standards, which is equal to 10. Each of this knowledge has some sub process that expressed how Project Management Knowledge implements. PMBOK has 10 Knowledge areas and 49 sub process and ISO 21500 has 10 subject groups and 39 sub process. Though, ISO 21500 has less sup process than PMBOK, it could challenge with older and more popular standards like PMBOK. Extracted results of section 3 are illustrated in Table 3.

\section{Table 3}

Findings of section 3

\begin{tabular}{|c|c|c|c|}
\hline \multicolumn{2}{|c|}{$\begin{array}{c}\text { ISO } 21500 \\
\text { Subject Group and Subprocesses }\end{array}$} & \multicolumn{2}{|c|}{$\begin{array}{c}\text { PMBOK } \\
\text { Project Management Knowledge and Subprocesses }\end{array}$} \\
\hline Integration & $\begin{array}{l}\text { Develop Project charter } \\
\text { Develop Project Plans } \\
\text { Direct Project Work } \\
\text { Control Project Work } \\
\text { Control Changes } \\
\text { Close project Phase or Project } \\
\text { Collect Lessons Learned }\end{array}$ & $\begin{array}{l}\text { Develop Project Charter } \\
\text { Develop Project Management Plan } \\
\text { Direct and Manage Project Work } \\
\text { Monitor and Control Project Work } \\
\text { Perform Integrated Change Control }\end{array}$ & Project Integration Management \\
\hline Scope & $\begin{array}{l}\text { Define Scope } \\
\text { Create Work Breakdown Structure } \\
\text { Define activities } \\
\text { Control Scope }\end{array}$ & $\begin{array}{l}\text { Plan Scope Management } \\
\text { Collect Requirements } \\
\text { Define Scope } \\
\text { Create WBS } \\
\text { Validate Scope } \\
\text { Control Scope }\end{array}$ & Project Scope Management \\
\hline Resource & $\begin{array}{l}\text { Establish Project Team } \\
\text { Estimate Resources } \\
\text { Define Project Organization } \\
\text { Develop Project Team } \\
\text { Control Resources } \\
\text { Manage Project Team }\end{array}$ & $\begin{array}{l}\text { Plan Human Resource Management } \\
\text { Acquire Project Team } \\
\text { Develop Project Team } \\
\text { Manage Project Team }\end{array}$ & $\begin{array}{l}\text { Project Human Resource Man- } \\
\text { agement }\end{array}$ \\
\hline Time & $\begin{array}{l}\text { Sequence Activities } \\
\text { Estimate Activity Durations } \\
\text { Develop Schedule } \\
\text { Control Schedule }\end{array}$ & $\begin{array}{l}\text { Plan Schedule Management } \\
\text { Define Activities } \\
\text { Sequence Activities } \\
\text { Estimate Activity Resources } \\
\text { Estimate Activity Durations } \\
\text { Develop Schedule } \\
\text { Control Schedule }\end{array}$ & Project time Management \\
\hline Cost & $\begin{array}{l}\text { Estimate Costs } \\
\text { Develop Budget } \\
\text { Control Costs }\end{array}$ & $\begin{array}{l}\text { Plan Cost Management } \\
\text { Estimate Costs } \\
\text { Determine Budget } \\
\text { Control Costs }\end{array}$ & Project Cost Management \\
\hline Risk & $\begin{array}{l}\text { identify Risks } \\
\text { Assess Risks } \\
\text { Treat Risks } \\
\text { Control Risks }\end{array}$ & $\begin{array}{l}\text { Plan Risk Management } \\
\text { Identify Risks } \\
\text { Perform Qualitative Risk Analysis } \\
\text { Perform Quantitative Risk Analysis } \\
\text { Plan Risk Responses }\end{array}$ & Project Risk Management \\
\hline Quality & $\begin{array}{l}\text { Plan Quality } \\
\text { Perform Quality Assurance } \\
\text { Perform Quality Control }\end{array}$ & $\begin{array}{l}\text { Plan Quality Management } \\
\text { Perform Quality Assurance } \\
\text { Control Quality }\end{array}$ & Project Quality Management \\
\hline Procurement & $\begin{array}{l}\text { Plan Procurement } \\
\text { Select Suppliers } \\
\text { Administer Contracts }\end{array}$ & $\begin{array}{l}\text { Plan Procurement Management } \\
\text { Conduct Procurements } \\
\text { Control Procurements } \\
\text { Close Procurements }\end{array}$ & $\begin{array}{l}\text { Project Procurement Manage- } \\
\text { ment }\end{array}$ \\
\hline Stakeholders & $\begin{array}{l}\text { Identify Stakeholders } \\
\text { Manage Stakeholders }\end{array}$ & $\begin{array}{l}\text { Identify Stakeholders } \\
\text { Plan Stakeholder Management } \\
\text { Manage Stakeholder Engagement } \\
\text { Control Stakeholder Engagement }\end{array}$ & $\begin{array}{l}\text { Project Stakeholders Manage- } \\
\text { ment }\end{array}$ \\
\hline
\end{tabular}

According to Table 3, we can compare both standards in Project Management Knowledge and their sup processes. Table 4 shows these differences. Both standards have 10 Project Management Knowledge, but the number of sub processes of each Project Management Knowledge is different. 
Table 4

Number of difference

\begin{tabular}{ccc}
\hline & ISO 21500 & PMBOK \\
\hline Integration & 7 & 6 \\
Scope & 4 & 6 \\
Time & 4 & 7 \\
Cost & 3 & 3 \\
Quality & 3 & 4 \\
Human Resource & 6 & 3 \\
Communication & 3 & 6 \\
Risk & 4 & 4 \\
Procurement & 3 & 4 \\
Stakeholder & 2 & 47 \\
Total & 39 & \\
\hline
\end{tabular}

Maybe the difference is associated with organizational culture. As we know ISO 21500 was published by ISO and PMBOK was published by Project Management Institute (PMI). ISO is a global organization and PMI is a local American organization and their stakeholders and experts have difference experience and culture too (Nilipour Tabatabaei \& Hosseini, 2014).

\section{Conclusion}

In this paper, a comparison between ISO 21500 and PMBOK has been performed. Concepts and definitions, processes of project management, subject groups and sub processes of each section were compared and excellence standard was shown in each subject group. Comparing two standards specifies strengths and weaknesses of each and it helps managers of organizations choose more suitable standards for their projects. Results were shown that in addition to a project or project portfolio, PMBOK standard focuses on project management too and this is a factor for increasing productivity and achieving the goals according to constraints. Also it was illustrated that Project Management Office (PMO) could be defined and interpreted. PMO is an office that plans and strategies of organizations are defined in it. ISO 21500 focuses on an individual project. Both of standards have 5 management processes in project. Their names are different in forth process but their concepts are identical.

Both of them have 10 areas described with their sub processes. Their names are deferent too. These subject groups are called Knowledge area in PMBOK and Subject Groups in ISO 21500. Although the 10 areas are similar to each other, but their sub processes are different. The "Management" word is used in all knowledge areas in PMBOK, but in ISO 21500 is just called area in subject groups. Maybe Management is more important concept in PMBOK.

Authors Recommendation to managers is that use both standards as complementary to each other and don't put a standard over another and use their text to promote of standard projects. Because of the lower manager's knowledge and information and neglect to standard in projects it cusses that we can't say which standard is more useful.

Finally, we recommended the readers to do more research on current scope and gain new results as follows,

- Apply knowledge areas and subject groups enclose all of sub processes in real case study and compare outcome results with the results of this survey in order to verify our results.

- Plan quality auditing of projects with ISO 21500. 


\section{Acknowledgement}

The authors would like to thank the anonymous referees for constructive comments on earlier version of this paper.

\section{References}

Chakir, A., Chergui, M., Medromi, H., \& Sayouti, A. (2015, November). An approach to select effectively the best framework IT according to the axes of the governance IT, to handle and to set up an objective IT. In Complex Systems (WCCS), 2015 Third World Conference on (pp. 1-8). IEEE.

da Fonseca, A. L. A., Monteiro, R. V. A., Junior, I. M., \& Farina, M. P. (2016). Proposal of a Project Management Model for Rural Distribution Networks Projects. IEEE Latin America Transactions, 14(8), 3713-3720.

Grau, N. (2013). Standards and Excellence in Project Management-In Who Do We Trust?. ProcediaSocial and Behavioral Sciences, 74, 10-20.

Gonçalves, R. Q., \& Von Wangenheim, C. G. (2016a). An Instructional Unit for Teaching Project Management Tools Aligned with PMBOK. In Software Engineering Education and Training (CSEET), 2016 IEEE 29th International Conference on (pp. 46-55). IEEE.

Gonçalves, R. Q., \& von Wangenheim, C. G. (2016b). Evaluating the Teaching of Project Management Tools through a Series of Case Studies. ICEIS 2016, 393.

Guerra-García, C., Juárez-Ramírez, R., Menéndez-Domínguez, V., Llamas, R., \& Montaño, O. (2016, April). Improving the project planning process considering artifacts with quality. In Software Engineering Research and Innovation (CONISOFT), 2016 4th International Conference in (pp. 15-20). IEEE.

Hammouch, H., Medromi, H., \& Sayouti, A. (2016). Designing Multi Agent System Architecture for Project Performance Based on PMBOK Standard. In Advances in Ubiquitous Networking (pp. 559570). Springer Singapore.

Hosseini, M. (2013). ISO 21500 Guidance on Project Management. International Organization Standardization. 12-14.

Labriet, T. (2012). Comparing PMBOK® Guide 4 th Edition, PMBOK ${ }^{\circledR}$ Guide $5^{\text {th }}$ ed., and ISO 21500.

Langston, C., \& Ghanbaripour, A. N. (2016). A Management Maturity Model (MMM) for projectbased organisational performance assessment. Construction Economics and Building, 16(4), 68-85.

Mas, A., Mesquida, A. L., Jovanović, M., \& Barceló, J. (2016). Lessons learned from 4-year empowering project management with TALAIA OpenPPM. Journal of Software: Evolution and Process, 28(11), 981-989.

Mesquida, A. L., Mas, A., Lepmets, M., \& Renault, A. (2014, November). Development of the project management SPICE (PMSPICE) framework. In International Conference on Software Process Improvement and Capability Determination (pp. 60-71). Springer International Publishing.

Mesquida, A. L., Jovanovic, M., \& Mas, A. (2016, September). Process improving by playing: Implementing best practices through business games. In European Conference on Software Process Improvement (pp. 225-233). Springer International Publishing.

Nilipour Tabatabaei, S.A., \& Hosseini, M. (2014). Project Management Standard, Full Analysis and Comparison. PMBOK $5^{\text {th }}$ and ISO 21500", 28-32.

Otero-Mateo, M., Pastor-Fernandez, A., \& Portela-Nuñez, J. M. (2014). Influence of standard ISO 21500 in the management of collaborative networks. In Materials Science Forum (Vol. 797, pp. 914). Trans Tech Publications.

Pinto, R., \& Dominguez, C. (2012). Characterization of the practice of project management in 30 Portuguese metalworking companies. Procedia Technology, 5, 83-92.

Project Management Institute (2013). Project Management Body of Knowledge. Project Management Institute, $5^{\text {th }}$ ed. 
Sanjuan, A. G., \& Froese, T. (2013). The Application of project management standards and success factors to the development of a project management assessment tool. Procedia-Social and Behavioral Sciences, 74, 91-100.

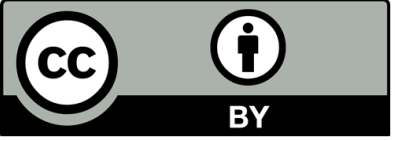

C 2017 by the authors; licensee Growing Science, Canada. This is an open access article distributed under the terms and conditions of the Creative Commons Attribution (CC-BY) license (http://creativecommons.org/licenses/by/4.0/). 